\title{
A Novel Methodology for Production Decline Analysis in Tight Gas Reservoirs: A Case Study from Sulige Tight Gas Field
}

\author{
Xiaofeng Li $\mathbb{D},{ }^{1,2}$ Lili Liu $\left(\mathbb{D},{ }^{1,2}\right.$ Jiaojiao Liu $\mathbb{D}^{1,2}$ Zhichao Li $\mathbb{D}^{1,2}$ and Xiaoliang Zhao $\mathbb{D}^{3}$ \\ ${ }^{1}$ PetroChina Changqing Oilfield Company Research Institute of Exploration and Development, Xi'an, China \\ ${ }^{2}$ National Engineering Laboratory for Exploration and Development of Low Permeability Oil/Gas Field, Xi'an, China \\ ${ }^{3}$ College of Petroleum Engineering, China University of Petroleum-Beijing, China
}

Correspondence should be addressed to Jiaojiao Liu; liujj69_cq@petrochina.com.cn

Received 6 December 2020; Revised 11 March 2021; Accepted 31 March 2021; Published 26 April 2021

Academic Editor: Bao Jia

Copyright (C) 2021 Xiaofeng Li et al. This is an open access article distributed under the Creative Commons Attribution License, which permits unrestricted use, distribution, and reproduction in any medium, provided the original work is properly cited.

Study shows that decline exponents of gas wells in Sulige Tight Gas Field vary during their life cycle. However, decline analysis methods with variable decline exponent have not been developed so far. To address this problem, a simple-yet-effective method is proposed. In this method, the fracture linear flow regime and the channel linear flow regime, which appear two straight lines on the coordinate axis $(1 / q$ vs. $\sqrt{t})$, respectively, are used to carry out the decline analysis. Each regime has a different slope and intercept (in the form of $1 / q$ vs. $\sqrt{t}$ ), which leads to a useful graphical technique for predicting gas rate. The graphical technique is verified by matching actual gas rate and predicting future gas rate trend. Theoretically, the influence of the two slopes and intercepts in the graphical technique on the rate decline is also studied. Aiming at decline analysis for tight gas wells with variable decline exponents, this paper proposes a novel method using linear flow characteristics, which ingeniously avoids the establishment of an empirical method to deal with variable decline exponent. The method in this study can help for better understanding of decline analysis of tight gas wells in a theoretical manner.

\section{Introduction}

As we all know, Arps decline-curve method [1] is not applicable for tight gas reservoir. The main reasons are that its assumptions are violated in tight gas wells. For example, tight gas wells rarely reach boundary-dominated flow even after several years of production, while Arps decline-curve method demands boundary-dominated flow. Moreover, Kupchenko [2] proved that decline exponent is variable for fractured tight gas wells. In linear flow regimes, decline exponent will be bigger than 1, until flow regime enters into boundary-dominated flow. For gas wells in some extreme low-permeability gas reservoirs, the decline exponent will be bigger than 1 in their life cycle.

To deal with the new problem, new methods are proposed. Duong [3] introduced an empirically decline model based on long-term linear flow for tight gas reservoirs. ILK et al. [4] proposed a method named Power law Exponential Decline to predict the reserves of unconventional reservoirs. For A. N. Duong method and ILK method, there are many parameters to be determined in the fitting process, so multiple solutions are inevitable. Matter et al. [5] proposed modified power law exponential decline. In 2009, Valko [6] proposed stretched exponential production decline method for shale gas. Joshi et al. [7] proposed a method which combined Duong model with hyperbolic decline model. Yu [8] presented a new improved methodology to determine a more accurate $b$ to be used in the Arps decline curve analysis for tight gas reservoirs by developing relationship between Qcum, Qcum, $t-\infty$, qt, and $t$. In general, the above methodologies are mainly empirical. Neal and Mian [9] presented a predictive technique by introducing linear flow equation. Dought and Moridis [10] developed a simple, Excel-based tool for the analysis of the complex problem of gas production from a hydraulically fractured tight/shale gas reservoir, based on curve fitting a semianalytical solution to production decline data. In Alem et al.'s [11] opinions, the traditional hyperbolic decline equation can be used to predict recovery from tight gas plays by selecting the right decline exponent 
in correspondence with flow regime. Mienzan and Asumadu [12] present a new set of rate-decline type curves to analyze and predict gas well performance. The rate-decline type curves have been developed based on a semianalytical model. However, the method they proposed whether is applicable to tight gas is not mentioned.

Unlike the approaches mentioned above, this paper developed a new approach to handle rate decline with variable decline exponent by utilizing fracture linear flow equation and channel flow equation, rather than establishing empirical equations.

In this paper, firstly, the field characteristic is presented. Then, we employ a numerical model to investigate gas rate and decline exponents in Sulige gas field. Third, the theory basis to draw the novel approach in this paper is elaborated. Forth, practical production data is used to validate the approach. Fifth, sensitivity analysis of slope $(m)$ and inter$\operatorname{cept}(s)$ is performed. Finally, a discussion about the novel approach is presented.

\section{Field Characteristic}

Sulige gas field is a large lithologic gas reservoir, characterized by braided river development. The effective reservoir formations are mainly isolated and stripped, with strong heterogeneity. Average formation thickness is $6 \sim 7 \mathrm{~m}$, porosity is $7.4 \sim 8.3 \%$, and average permeability is $0.036 \mathrm{md}$. Reservoir depth ranges from 3450 to $3730 \mathrm{~m}$; average formation pressure is $30 \mathrm{MPa}$, and formation temperature is $110^{\circ} \mathrm{C}$.

\section{Decline Exponent Investigation}

For the purpose of investigating decline exponents for tight gas wells in Sulige gas field, we commence our study by using numerical simulation method. According to reservoir characterization and fracturing treatment of Sulige tight gas field, reservoir model can be simplified into rectangle reservoir models centered a fracture for the convenience of analysis (shown in Figure 1). Physical properties used in the reservoir model present in field characteristic. Gas wells produce at constant bottom flowing pressure.

Three cases are simulated at different formation permeability, with certain fracture half-length, fracture conductivity, and drainage area. Simulated gas rate data are shown in Figure 2. By using Equation (1) [13], decline exponent can be obtained by calculating simulated gas rate data (shown in Figure 3).

$$
b=\frac{\left((1 / D)-\left(1 / D_{i}\right)\right)}{t}
$$

As Figure 3 shows, for permeability less than $0.01 \mathrm{md}$, decline exponents will be bigger than 1 for a long time; while for permeability between $0.01 \mathrm{md}$ and $0.1 \mathrm{md}$, decline exponents will be bigger than 1 in initial phase of production, smaller than 1 in late phase of production. However, decline exponents for traditional Arps decline method are between 0 and 1. Therefore, traditional Arps decline method will not be applicable.

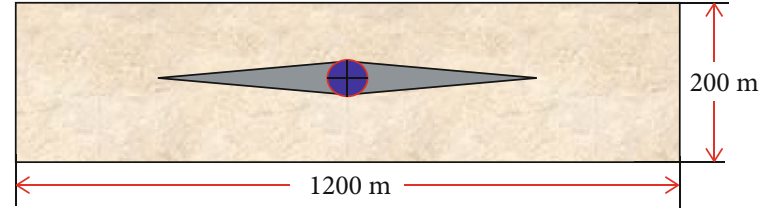

Figure 1: The rectangle reservoir model.

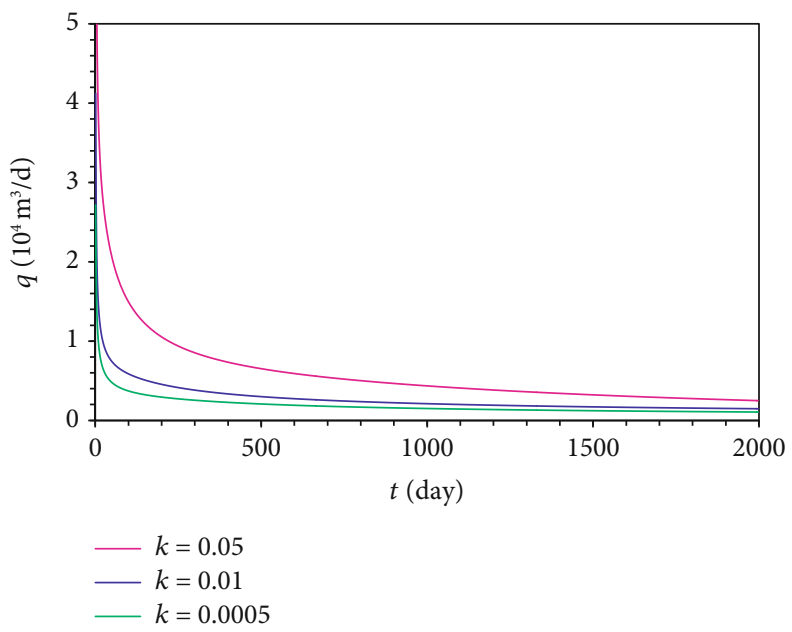

FIgURE 2: Rate vs. time with varied permeability.

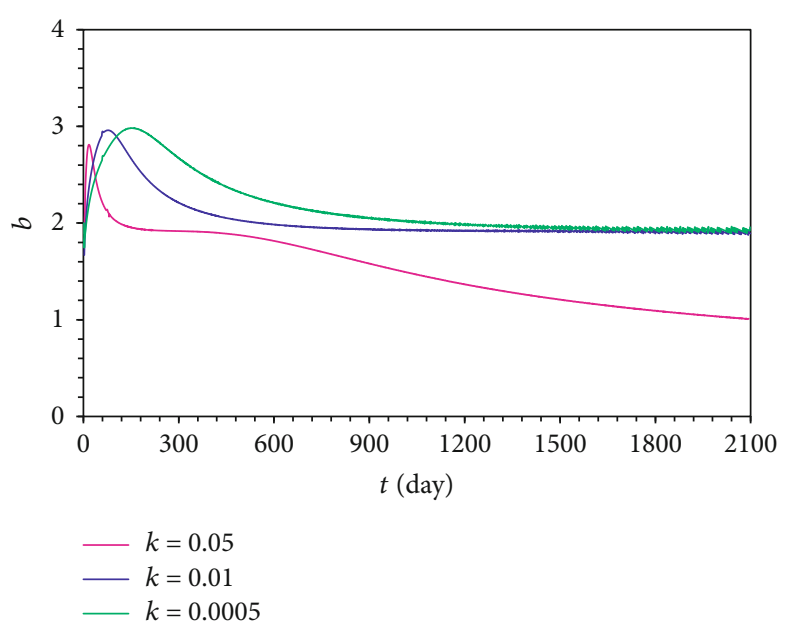

FIGURE 3: Decline exponent $b$ vs. time with varied permeability.

\section{Theory Basis}

As the invalidation of Arps model, we turned to find new method. According to relevant reservoir knowledge, for narrow and striped tight formations, flow regime can be divided into three regimes, which are linear flow regime, elliptical flow regime, and pseudoradial flow, boundary-dominated flow. Here, linear flow is of importance for the new method.

Theoretically, there may be three kinds of linear flow, fracture-related linear flow [14], channel-related linear flow [15], Watterbargen linear flow [16], equations show in Table 1. Owing to the fracture length always smaller than 
TABLE 1: Working equation for different linear flow.

\begin{tabular}{lc}
\hline Linear flow & Working equation \\
\hline Fracture linear flow & $1 / q_{D}=\sqrt{\pi t_{D}} / \psi_{D}$ \\
Channel linear flow & $1 / q_{D}=\sqrt{\pi t_{D}}$ \\
Wattenbarger linear flow & $1 / q_{D}=(\pi / 2) \sqrt{\pi t_{D}}$ \\
\hline
\end{tabular}

channel width, fracture linear flow and channel linear flow will appear in most tight gas wells in Sulige tight gas field. Therefore, in this paper, we mainly highlight fracture linear flow and channel linear flow. From Table 1, we can see, any kind of linear flow, the inverse dimensionless rate vs. dimensionless square time is linear in coordinate system. Hence, it is possible to utilize the relationship to perform decline analysis. The following is detailed information.

4.1. Fracture Linear Flow. For fracture linear flow, dimensionless $q_{D}$ for constant pressure will be given:

$$
q_{D}=\frac{\psi_{D}}{\sqrt{\pi t_{D}}}
$$

According to the definition of dimensionless variables, Equation (1) can be simplified to

$$
\frac{1}{q_{g}}=m_{1} \sqrt{t}+s
$$

where

$$
m_{1}=\frac{P_{s c} T \sqrt{\pi}}{2 T_{s c} \Delta \psi \sqrt{\mu C_{t}} \sqrt{k \phi} h x_{f}} .
$$

4.2. Channel Linear Flow. For channel linear flow, dimensionless $q_{D}$ for constant pressure will be given:

$$
\frac{1}{q_{D}}=\sqrt{\pi t_{D}}
$$

Through dimensioning, Equation (5) can be simplified to

$$
\frac{1}{q_{g}}=m_{2} \sqrt{t}+s,
$$

where

$$
m_{2}=\frac{P_{s c} T \sqrt{\pi}}{2 h L T_{s c} \Delta \psi \sqrt{k \phi \mu C_{t}}} .
$$

Equation (3) and Equation (6) show that $1 / q_{g}$ and $t^{1 / 2}$ are linearly related during the fracture and channel linear flow.
The total volume produced from $t_{1}$ to $t_{2}$ can be found by integrating Equation (6):

$$
Q=\frac{2}{m^{2}}\left\{m\left(\sqrt{t_{1}}-\sqrt{t_{2}}\right)+s\left[\ln \left(s+m \sqrt{t_{1}}\right)-\ln \left(s+m \sqrt{t_{2}}\right)\right]\right\} .
$$

Looking at Equation (7), for channel flow, the slope $m$ can be rewritten as

$$
m=A B\left(\frac{1}{h L \sqrt{k \phi}}\right),
$$

where $A$ and $B$ are, respectively, defined as:

$$
\begin{aligned}
& A=\frac{P_{s c} \sqrt{\pi}}{2 T_{s c}}, \\
& B=\frac{T}{\Delta \psi \sqrt{\mu C_{t}}} .
\end{aligned}
$$

$A$ can be treated as a constant independent of a particular well and independent of a particular reservoir, and $B$ is independent of particular well but dependent on its pressure difference, which impose minor effect on the linear relationship between $1 / q_{g}$ and $t^{1 / 2}$. Therefore, the variation in $m$ among different wells in the same field would be attributable to changes in permeability, thickness, and channel width. For a given tight gas reservoir, porosity varies little compared with permeability and thickness and can be treated as a constant. As a result, the differences in observed slopes $m$ for wells in a particular area can often be primarily attributed to variations in the term $1 /(h L \sqrt{k \phi})$.

Equations (3) and (6) both embodies linear relationship in the form of $1 / q_{g}$ vs. $t^{1 / 2}$ theoretically. Simulated production performance for long stripped formation verified that relationship. Figure 4 clearly displays these two linear relationships.

\section{Practical Application}

In order to validate the theory established, practical application is essential. Equations (6) and (8) were applied to predict and match gas well production performance from Sulige tight gas field. Well information is provided in Table 2. By plotting rate/time production data $1 / q_{g}$ vs. $t^{1 / 2}$, determining the $m$ and $s$, then utilizes $m$ and $s$ to match rate/time in a coordinate system. Plots $\left(1 / q_{g}\right.$ vs. $\left.t^{1 / 2}\right)$ for well A, well B, well $\mathrm{C}$, well $\mathrm{D}$, are presented in Figures $5-8$, which exhibit straight-line behavior. Aided by straight-line, matching curves $\left(q_{g}\right.$ vs. $\left.t\right)$ for well A, well B, well C, and well D are presented in Figures 9-12. Figures 5-8 suggest that linear flow was dominant for well A, well B, and well C. In addition, taking $\mathrm{D}$ well for example, launching prediction for well performance in the future during linear flow is also plausible. For D well, linear relationship was generated only by year 1 and year 2, and year 3 production data is projected in Figures 8 and 12 . 


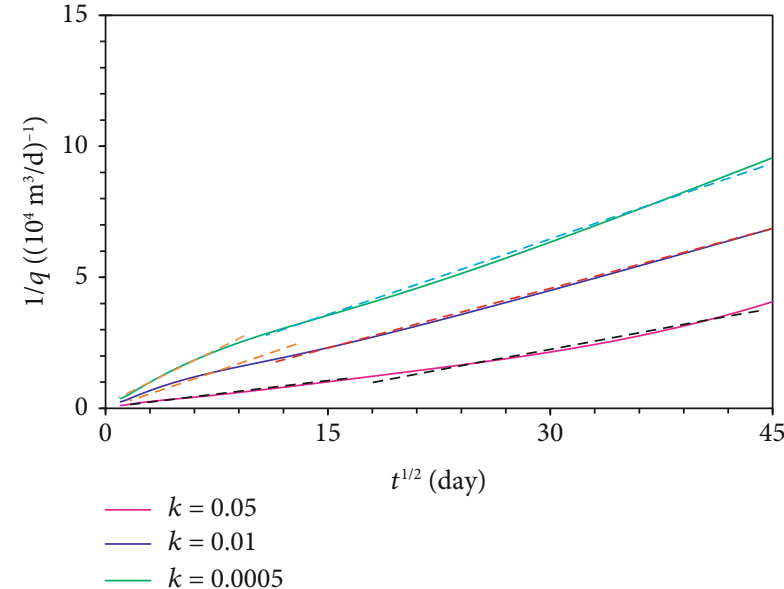

FIGURE 4: Cases with varied slope same intercept.

TABLE 2: Reservoir and rock data.

\begin{tabular}{lcccccc}
\hline Well name & $\mathrm{Pi}(\mathrm{MPa})$ & $T\left({ }^{\circ} \mathrm{C}\right)$ & $K(\mathrm{mD})$ & $h(\mathrm{~m})$ & $\varphi(\%)$ & $\mathrm{Sw}(\%)$ \\
\hline Well A & 31.2 & 110 & 0.021 & 5.4 & 6.2 & 55 \\
Well B & 30.9 & 112.3 & 0.058 & 12.5 & 7.2 & 57 \\
Well C & 31.2 & 115.1 & 0.079 & 15.8 & 6.8 & 54 \\
Well D & 31.8 & 112.4 & 0.046 & 16.8 & 6.4 & 56.5 \\
\hline
\end{tabular}

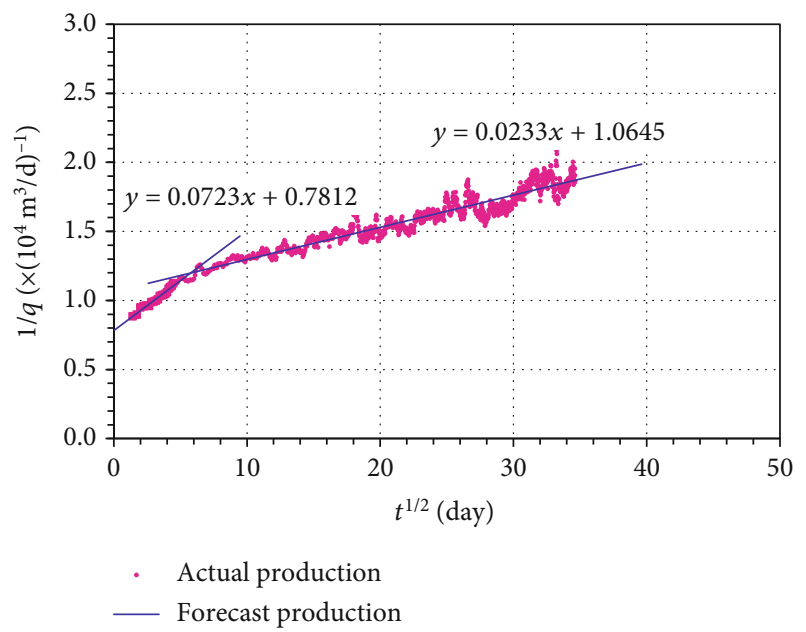

FIGURE 5: $1 / q_{g}$ vs. $t^{1 / 2}$ matching plot for A well.

\section{Sensitivity Analysis of $m$ and $s$}

Equation (8) can be employed to describe each gas well's production performance during channel linear flow. Slope $m$ and intercept $s$ dominate gas rate decline tendency. To examine the effect of these two variables on production decline, a sensitivity analysis was performed. Figures 13 16 show the results. Figure 13 shows the $1 / q_{g}$ vs. $t^{1 / 2}$ curves where $m$ is varied but $s$ is constant, Figure 14 corresponds $q_{g}$ vs. $t$ curves. Figure 15 shows the $1 / q_{g}$ vs. $t^{1 / 2}$ curves where $s$ is varied but $m$ is constant; Figure 16 is corresponding $q_{g}$ vs. $t$ curves. Figure 13 shows that $m$ is indicative of the strength

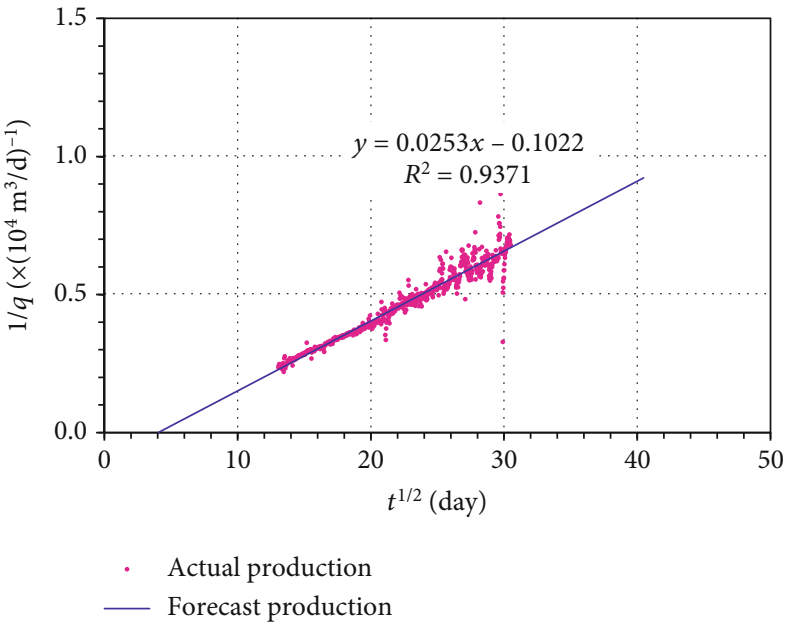

Figure $6: 1 / q_{g}$ vs. $t^{1 / 2}$ matching plot for B well.

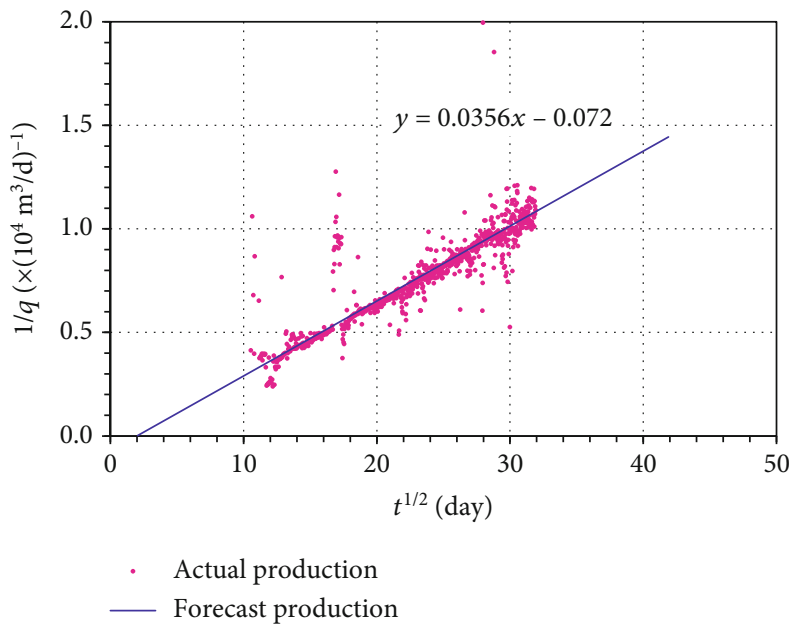

Figure $7: 1 / q_{g}$ vs. $t^{1 / 2}$ matching plot for C well.

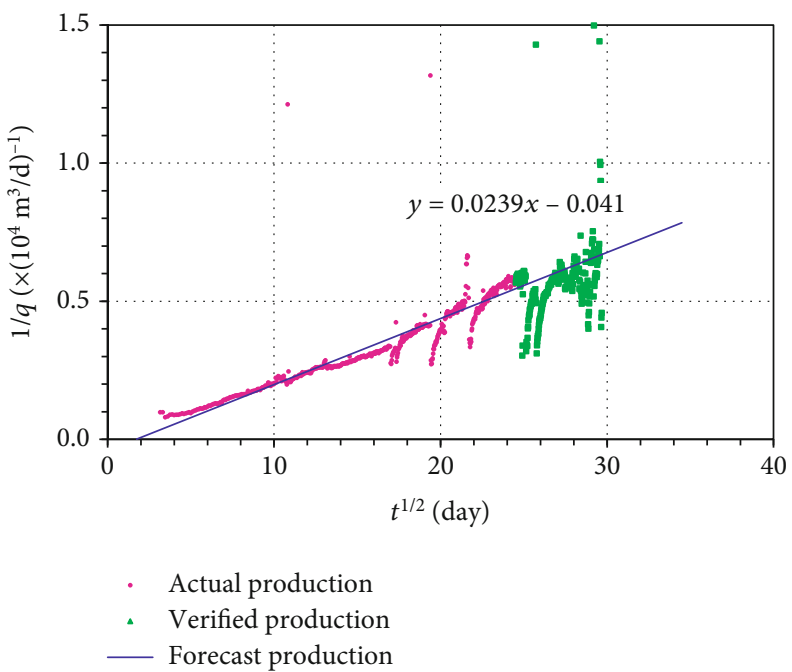

FIGURE $8: 1 / q_{g}$ vs. $t^{1 / 2}$ matching plot for D well. 


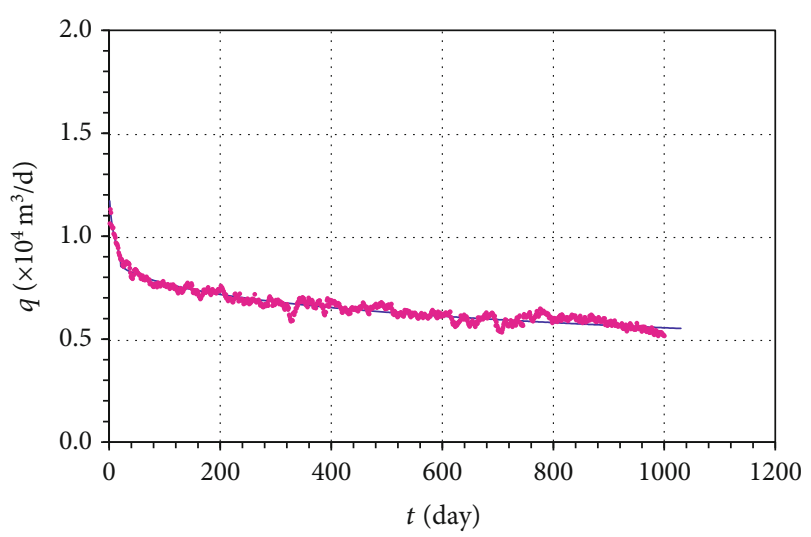

- Actual production

— Forecast production

Figure 9: $q_{g}$ vs. $t$ matching plot for A well.

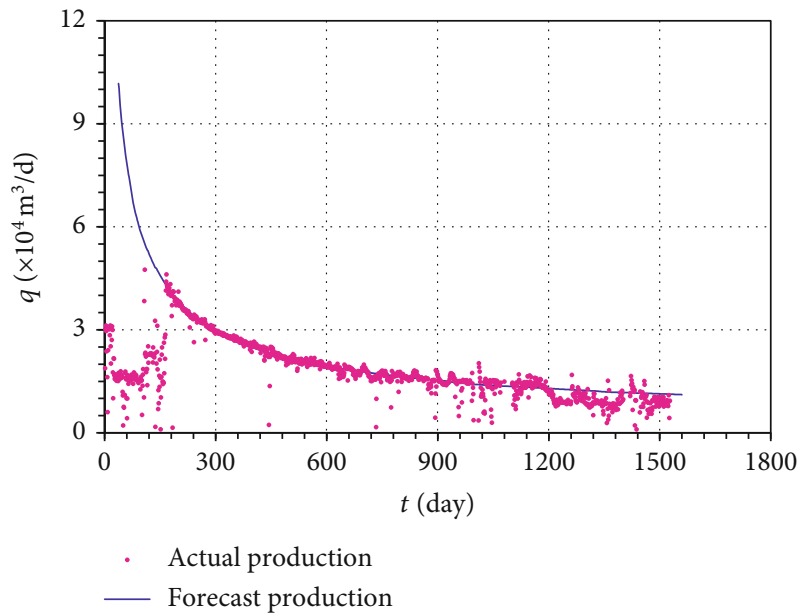

Figure 10: $q_{g}$ vs. $t$ matching plot for B well.

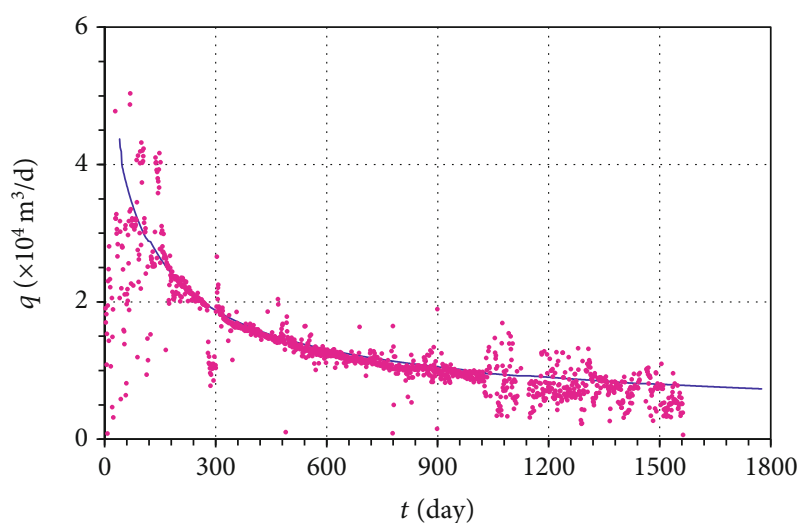

- Actual production

— Forecast production

Figure 11: $q_{g}$ vs. $t$ matching plot for C well.

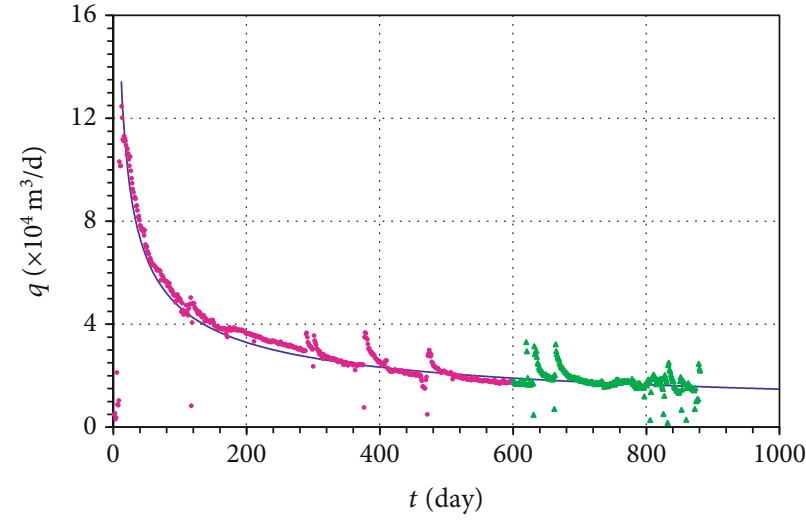

- Actual production

- Verified production

— Forecast production

Figure 12: $q_{g}$ vs. $t$ matching plot for D well.

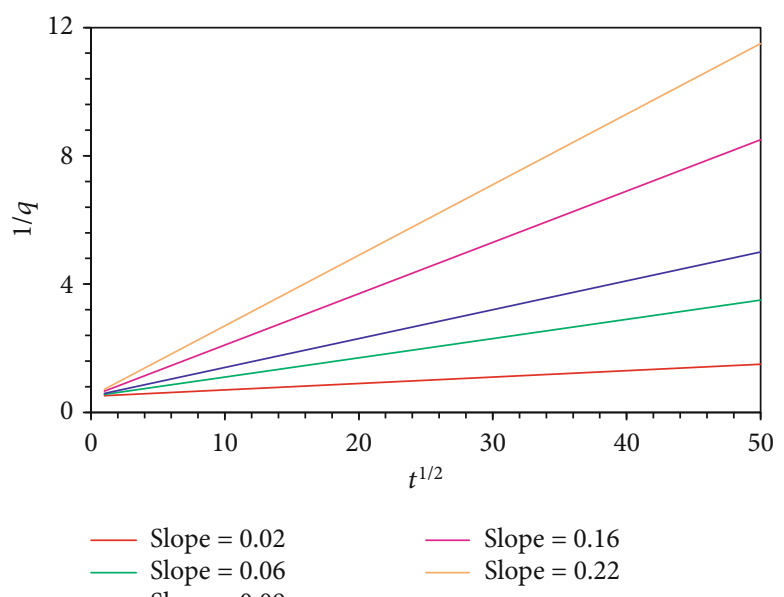

Figure 13: Cases with varied slope same intercept.

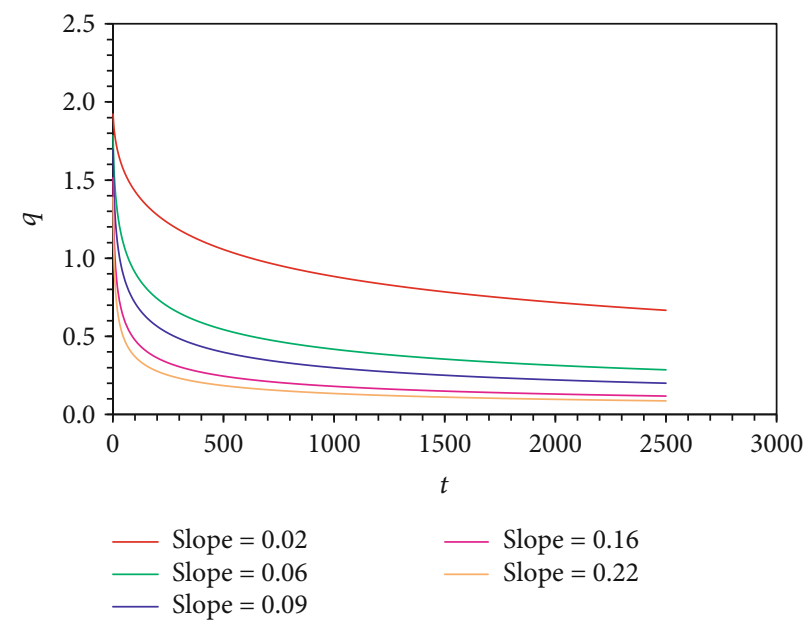

FIGURE 14: Rate/time curve with varied slope same intercept. 


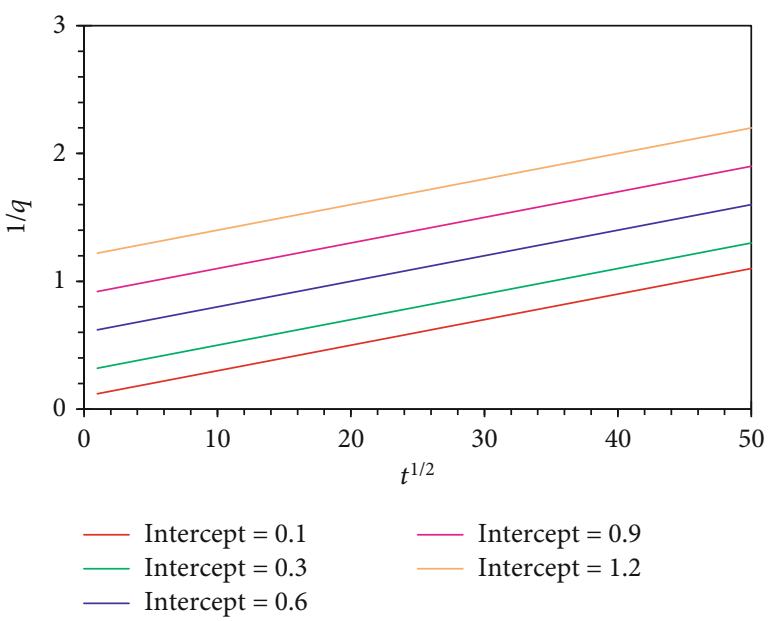

FIGURE 15: Cases with varied intercept and same slope.

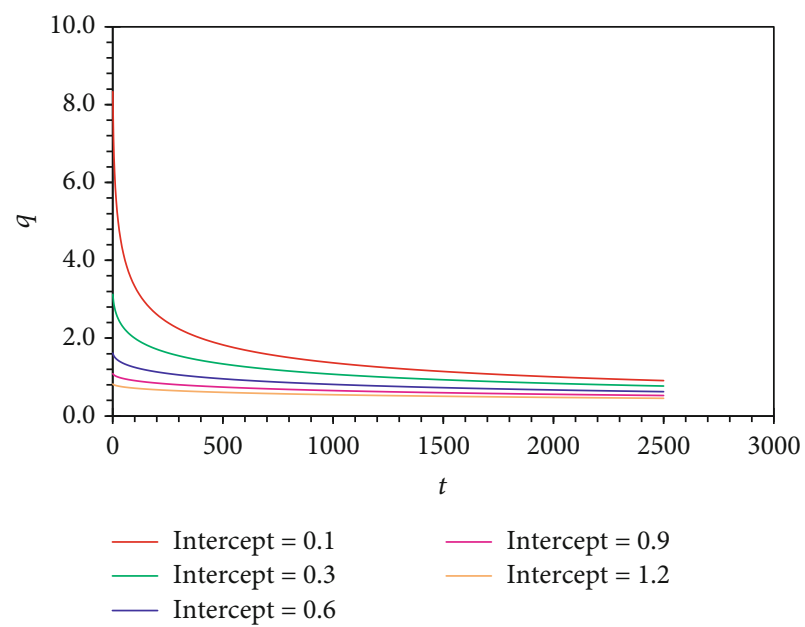

FIGURE 16: Rate/time curve with varied intercept and same slope.

of well; a small $m$ predicts a better production performance. Figure 15 shows that intercept $s$ is only an indication of near-wellbore conditions.

\section{Discussion}

In this paper, we focus on taking advantage of linear behaviors in tight gas wells to predict well performance, and the results show well-suited. It is smart to bypass establishing a model considering variable decline exponent. Also, utilizing linear flow model to promote decline analysis is more convincing than empirical methods. However, the idea does not involve the circumstance when some gas wells enter into boundary-dominated flow. Combining the approach developed in this paper with Arps model will be a good idea. Besides, given the point of this paper is decline analysis, so distinguishing channel linear flow from Watterbarger linear flow is not discussed in detail. The reason we highlight channel linear flow in this paper is that the fracture length for most gas wells in Sulige tight gas field is smaller than the drainage boundary. Hence, Watterbarger linear flow can be excluded in most cases. The only possibility for long-term linear flow would be channel linear flow.

\section{Summary and Conclusions}

(1) An effective novel approach for predicting future gas rate and EUR has been developed for tight gas wells by using linear flow

(2) The inverse of rate vs. the square of time is observed to fit a straight line in Sulige tight gas field and same gas field, which can forecast well performance accurately before pseudoradial flow

(3) The slope $m$ obtained from fitting can be used to indicate the quality of gas formation

(4) It is possible to match the entire production history for tight gas wells by combining the approach developed in this paper with Arps model

\section{Nomenclature}

$b$ : Decline exponent, dimensionless

D: Decline rate, \%

Di: Initial decline rate, $\%$

A: Defined in Equation (10)

$B$ : Defined in Equation (11)

Ct: Total system compressibility, $\mathrm{Pa}^{-1}$

Q: Cumulative gas produced

$h$ : Formation thickness, $\mathrm{m}$

$k$ : Formation permeability, md

$m$ : Slope of inverse rate vs square root of time

$\Delta \psi$ : Real gas pseud pressure change, $\mathrm{Pa} / \mathrm{s}$

$P_{s c}:$ Standard pressure, $\mathrm{Pa}$

$q_{g}$ : Flow rate, measured at standard conditions

$q_{D}$ : Dimensionless rate, $q_{D}=\left(q_{g} P_{s c} T\right) /\left(2 k h T_{s c} \psi_{i}\right)$ (when fracture linear flow), $q_{D}=\left(q_{g} P_{s c} T\right) /\left(2 k h T_{s c} \Delta \psi\right)$ (when channel linear flow)

$s$ : Inverse rate change caused by skin effects

$t$ : Time, $s$ or day

$t_{D}$ : Dimensionless time, $t_{D}=k t /\left(\phi \mu c_{t} x_{f}^{2}\right)$ (when fracture linear flow), $t_{D}=k t /\left(\phi \mu c_{t} L^{2}\right)$ (when channel linear flow)

$T: \quad$ Reservoir temperature, $\mathrm{K}$

$T_{s c}:$ Standard temperature, $\mathrm{K}$

$x_{f}:$ Fracture half-length, $\mathrm{m}$

L: $\quad$ Channel width, $\mathrm{m}$

$\mu$ : $\quad$ Gas viscosity, pa.s

$P_{i}: \quad$ Initial Pressure, $\mathrm{MPa}$

$\varphi: \quad$ Effective Porosity, \%

$S_{\mathrm{w}}$ : Initial Gas Saturation, \%.

\section{Data Availability}

The data used to support the findings of this study are available from the corresponding author upon request. 


\section{Conflicts of Interest}

The authors declare that they have no conflicts of interest.

\section{Acknowledgments}

This study was financially supported by the National Science Technology Major Project (No. 2016ZX05047004003).

\section{References}

[1] J. J. Arps, "Analysis of decline curves," Transactions of the AIME, vol. 160, no. 1, pp. 228-247, 1945.

[2] C. L. Kupchenko, B. W. Gault, and L. Mattar, "Tight gas production performance using decline curves," in CIPC/SPE Gas Technology Symposium 2008 Joint Conference, Calgary Alberta, Canada, June 2008.

[3] A. N. Duong, "An unconventional rate decline approach for tight and fracture-dominated gas wells," in Canadian Unconventional Resources and International Petroleum Conference, Calgary, Alberta, Canada, October 2010.

[4] D. Ilk, J. A. Rushing, A. D. Perego, and T. A. Blasingame, "Exponential vs. hyperbolic decline in tight gas sands -understanding the origin and implications for reserve estimates using Arps' decline curves," in SPE Annual Technical Conference and Exhibition, Denver, CO, USA, September 2008.

[5] L. Matter and S. Moghadam, "Modified power law exponential decline for tight gas," in Canadian International Petroleum Conference (CIPC), Calgary, Alberta, Canada, June 2009.

[6] P. Valko, "Assigning value to stimulation in the Barnett shale-a simultaneous analysis of 7000 plus production histories and well completion records," in SPE Hydraulic Fracturing Technology Conference, The Woodlands, TX, USA, January 2009.

[7] K. Joshi and W. J. Lee, "Comparison of various deterministic forecasting technique in shale gas reserviors," in SPE Hydraulic Fracturing Technology Conference, The Woodlands, TX, USA, February 2013.

[8] S. Yu, "Best practice of using empirical methods for production forecast and EUR estimation in tight/shale gas reservoirs," in SPE Unconventional Resources Conference Canada, Calgary, Alberta, Canada, November 2013.

[9] D. B. Neal and M. A. Mian, "Early-time tight gas production forecasting technique improves reserves and reservoir description," SPE Formation Evaluation, vol. 4, no. 1, pp. 25-32, 1989.

[10] C. Dought and G. J. Moridis, "The use of the bimodal production decline curve for the analysis of hydraulically fractured shale/tight gas reservoirs," in Proceedings of the 6th Unconventional Resources Technology Conference, Houston, TX, USA, July 2018.

[11] M. Alem, T. Baig, and A. Muggeridge, "Predicting the performance of tight gas reservoirs," in SPE Europec featured at 81st EAGE Conference and Exhibition, London, England, UK, June 2019.

[12] F. K. Mienzan and D. Y. Asumadu, "Gas rate-decline type curve analysis using a semi-analytical model," in SPE Nigeria Annual International Conference and Exhibition, Virtual, August 2020.

[13] J. P. Spivey, J. H. Frantz Jr., J. R. Williamson, and W. K. Sawyer, "Applications of the transient hyperbolic exponent," in SPE Rocky Mountain Petroleum Technology Conference, Keystone, CO, USA, May 2001.
[14] T. Chen and R. Kry, "Pressure buildup from a vertically fractured low-permeability formation(includes associated paper 12938)," Journal of Petroleum Technology, vol. 34, no. 4, pp. 917-924, 1982.

[15] L. Larsen and M. Hovdan, "Analyzing well test data from linear reservoirs by conventional methods," in SPE Annual Technical Conference and Exhibition, Dallas, TX, USA, September 1987.

[16] J. A. Arévalo-Villagrán, R. A. Wattenbarger, F. SamaniegoVerduzco, and T. T. Pham, "Production analysis of longterm linear flow in tight gas reservoirs: case histories," in Paper SPE 71516 presented at the 2001 SPE Annual Technical Conference and Exhibition, New Orleans, LA, USA, September-October 2001. 